\title{
Estradiol: micrograms or milligrams
}

\author{
Jeremy M W Kirk, Nalin Wickramasuriya and Nicholas J Shaw \\ Department of Endocrinology, Birmingham Children's Hospital, Steelhouse Lane, Birmingham B4 6NH, UK
}

Correspondence

should be addressed

to J M W Kirk

Email

Jeremy.kirk@bch.nhs.uk

\section{Summary}

Estrogen is used to induce puberty in peripubertal girls with hypogonadism. Although both synthetic and natural forms are available, along with different routes of administration, in the UK oral ethinyl estradiol and the low-dose oral contraceptive pill are commonly used as hormone replacement therapy for practical reasons. We present five peripubertal girls (aged 12.514.9 years) with hypogonadism (two with primary hypogonadism due to Turner syndrome and three with central (secondary) hypogonadism as part of multiple pituitary hormone deficiency) who for a variety of reasons have received milligram doses of estradiol $\left(E_{2}\right)$ in error for between 6 weeks and 6 months, instead of the expected microgram doses of ethinyl estradiol. Although there are no direct comparisons in peripubertal girls between synthetic and natural estrogens, all girls had vaginal bleeding whilst receiving the milligram doses and have ended up with reduced final heights, below the 9th centile in 1 and below the 2 nd centile in 4 . Whilst reduction in final height may be part of the underlying condition (especially in Turner syndrome) the two girls with height predictions performed prior to receiving the estrogen overdose have not achieved their predicted height. Estrogen is one of the few drugs which is available in both milligram and microgram formulations. Clinicians need to be alert to the possibility of patients receiving the wrong formulation and dosage in error.

\section{Learning points:}

- Girls with primary and secondary gonadal failure require assistance with pubertal induction.

- Although several different formulations and route of administration are available, for practical reasons, the majority of girls in the UK receive oral ethinyl estradiol.

- Estrogen preparations are available in both milligram and microgram formulations, with potential for receiving the wrong dose.

- Girls receiving milligram rather than microgram preparations all had vaginal bleeding and a short final height.

\section{Background}

In pediatric practice, there are several groups of female patients who fail to have spontaneous pubertal development. This includes those with primary gonadal failure such as Turner syndrome, or central gonadotropin deficiency secondary to hypothalamo-pituitary dysfunction, e.g. intracranial tumors and their treatment. The role of hormone replacement therapy (HRT) in these patients is to i) mimic physiologic puberty, ii) enhance normal growth, iii) induce and maintain normal menstruation, iv) support normal bone maturation and calcification, v) initiate and maintain normal brain cell growth and plasticity and vi) preserve the woman's psychosexual well-being (1).

Whereas in adult practice in the UK the natural estrogen $17-\beta$ estradiol is more commonly prescribed as HRT, most UK pediatric endocrinologists use ethinyl estradiol to initiate puberty on the grounds of convenience $(2,3)$ and also unavailability of low-dose oral natural estrogen preparations. We report five cases of iatrogenic vaginal bleeding due to incorrect prescribing of estradiol in young female hypogonadal patients. 


\section{Case presentation}

See also summary in Table 1.

\section{Case 1}

This girl has a Turner syndrome mosaic karyotype (45X/46 XY(dic)). Because of her Y chromosome material, she had a prophylactic gonadectomy performed in childhood. In addition to growth hormone $(\mathrm{GH})$ therapy, the decision to start estrogen replacement was made at 14.9 years. A letter to the general practitioners was written requesting them to prescribe $2 \mu \mathrm{g}$ ethinyl estradiol daily. At the next clinic attendance 6 months later the patient reported frequent periods with breakthrough vaginal bleeding, in association with significant mood swings. On checking, it was discovered that she had been receiving $2 \mathrm{mg}$ estradiol valerate (Zumenon, Solvay Healthcare Ltd, Southampton, Hampshire, UK) daily. The estradiol was stopped temporarily for 2 weeks, and the patient was then recommenced uneventfully on $2 \mu \mathrm{g}$ a day of ethinyl estradiol. Her final height is now $151.7 \mathrm{~cm}$, achieved at 17.0 years of age.

\section{Case 2}

This girl has hypopituitarism $(\mathrm{GH}$, adrenocorticotropic hormone (ACTH), thyroid-stimulating hormone (TSH) and gonadotropin) (luteinising hormone (LH) and follicle-stimulating hormone (FSH)) deficiency secondary to cranial irradiation for a metastatic medulloblastoma. She was commenced on estrogen replacement (initially ethinyl estradiol $2 \mu$ g daily) at the age of 13.3 years. Six months later, her ethinyl estradiol dose was increased to $5 \mu \mathrm{g}$ daily. Whilst this was intended to be given as half a $10 \mu \mathrm{g}$ tablets of ethinyl estradiol it was instead erroneously given as $2 \times 2 \mu \mathrm{g}$ tablets of ethinyl estradiol and a $1 \mathrm{mg}$ tablet of 17- $\beta$ estradiol. She was reported to have had some vaginal bleeding. Once the mistake was noticed she was recommenced on $6 \mu \mathrm{g}$ of ethinyl estradiol administered as $3 \times 2 \mu \mathrm{g}$ tablets daily. Her final height is $151.7 \mathrm{~cm}$, achieved at the age of 16.4 years of age, having had an estimated height prediction (TW-2 method) prior to the estrogen overdose of $154.3 \mathrm{~cm}$.

\section{Case 3}

This girl has Turner syndrome (45XO karyotype), with no ovarian tissue visible on pelvic ultrasound (so-called 'streak gonads'). As well as receiving GH therapy, the decision to start estrogen replacement was made at the age
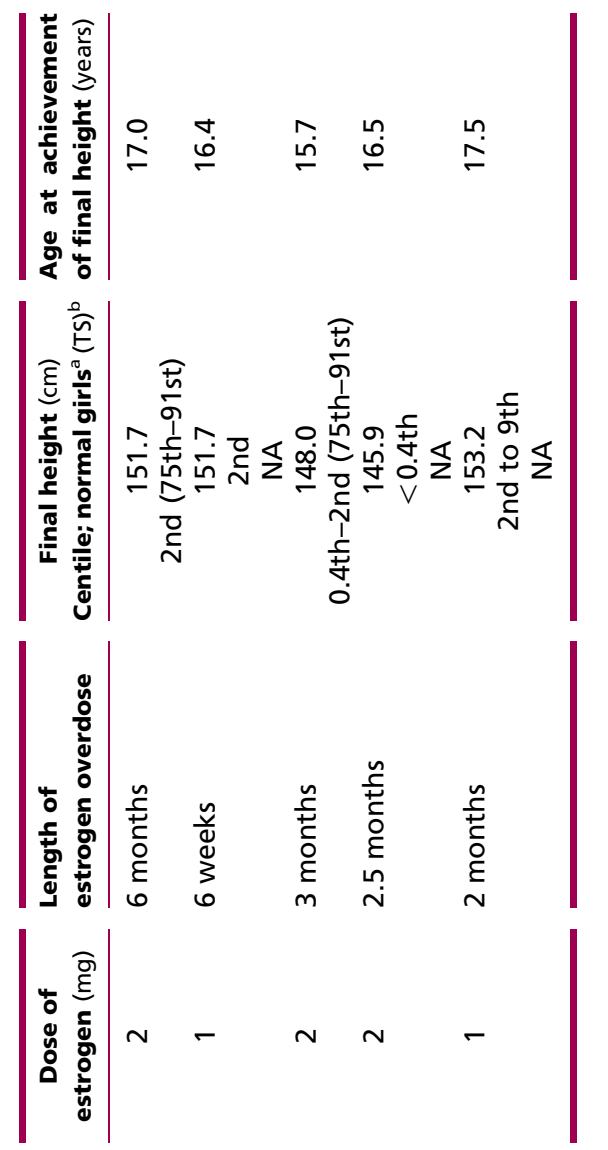

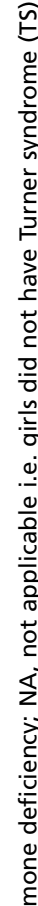

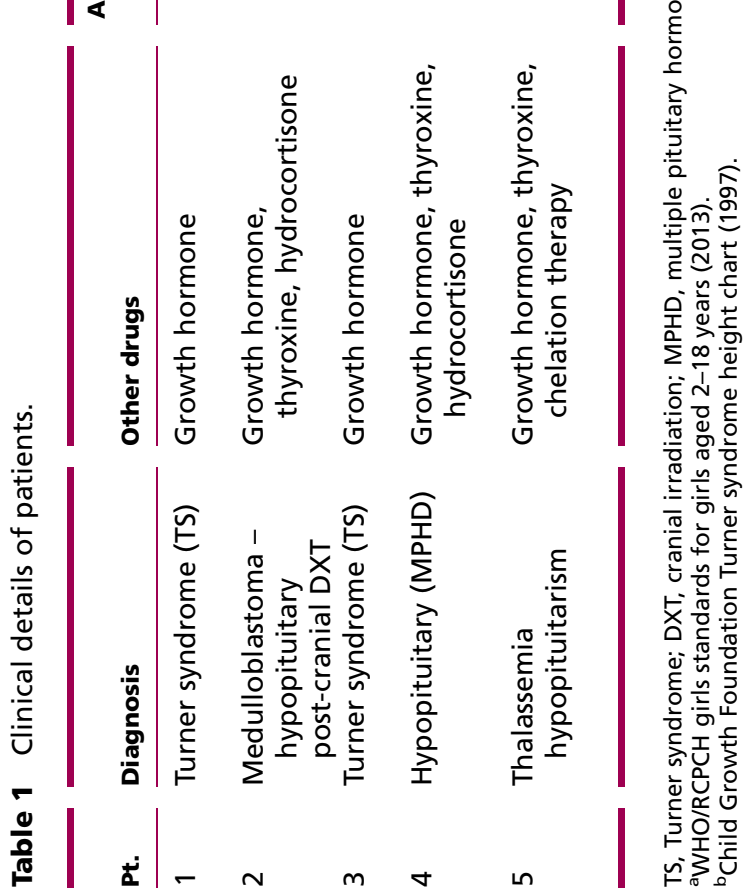

http://www.edmcasereports.com 
of 14.5 years. Due to a transcription error in a letter, rather than commencing ethinyl estradiol $2 \mu \mathrm{g}$ daily, she was started on $2 \mathrm{mg}$ estradiol valerate (Zumenon, Solvay Healthcare Ltd) instead. Three months later, she was reported to have frequent, protracted, heavy periods. On the discovery of the drug error, her estrogen therapy was stopped. She was uneventfully restarted on $5 \mu \mathrm{g}$ ethinyl estradiol daily several months later. She has now achieved a final height of $148.0 \mathrm{~cm}$ at 15.7 years of age.

\section{Case 4}

This girl has multiple pituitary hormone deficiencies (GH, ACTH, TSH and gonadotrophins (LH and FSH)) and is receiving therapy with $\mathrm{GH}$, thyroxine and hydrocortisone. Estrogen replacement (ethinyl estradiol $2 \mu \mathrm{g}$ daily) was commenced at 12.5 years of age. Mistakenly, the patient received estradiol valerate $2 \mathrm{mg}$ for $2 \frac{1}{2}$ months following a dispensing error. Once this was noticed, she was changed back to $2 \mu \mathrm{g}$ ethinyl estradiol (as originally prescribed) which resulted in some vaginal spotting for a week, presumably due to an estrogen withdrawal bleed. She had marked prominence of nipples and areolae, but was otherwise prepubertal. She has now achieved a final adult height of $145.9 \mathrm{~cm}$ at 16.5 years of age, having had a height prediction (TW-2 method) of $152.8 \mathrm{~cm}$ prior to commencing estrogen.

\section{Case 5}

This girl has $\beta$-thalassemia major, and is maintained on a regular transfusion regime. She was found to have $\mathrm{GH}$ deficiency, with secondary hypothyroidism and gonadotropin deficiency at the age of 12.1 years, presumed secondary to iron overload. At this stage, she was commenced on GH therapy and also ethinyl estradiol (initially $2 \mu \mathrm{g}$ a day). At 13.6 years of age, she received estrogen $1 \mathrm{mg}$ a day for 2 months in addition to her prescribed $5 \mu \mathrm{g}$ a day of ethinyl estradiol. This produced two cycles of vaginal bleeding, with subsequent breakthrough bleeding when the ethinyl estradiol was increased to $10 \mu \mathrm{g}$ a day. She has now achieved a final height of $153.2 \mathrm{~cm}$ at 17.5 years of age.

\section{Discussion}

Estrogen replacement has an important role in the management of puberty in girls with gonadal failure. The secretion of estrogen during adolescence contributes to the growth spurt of early puberty by affecting cartilage growth and an increase in GH secretion, but also produces epiphyseal fusion (4). Estrogen can be administered via depot and gel formulations and with the availability of patches which can be cut without damaging their integrity, transdermally. Whilst the latter are probably now the preferred method (5), most regimens within the UK have and continue to be based around low-dose oral estrogen therapy. The oral estrogen formulations commonly used are either 17- $\beta$ estradiol or ethinyl estradiol. The use of the latter in pediatrics is driven by practicalities rather than science (3). It is the most convenient low-dose estrogen available for pubertal induction, available in 2 and $10 \mu \mathrm{g}$ tablets, whereas, unlike in other countries, $17-\beta$ estradiol is not available within the UK in low-dose oral formulations. The oral contraceptive pill (OCP) is also considered more 'peer-friendly' to young women than HRT (3), which is commonly used in post-menopausal women. Unlike HRT, however, which provides constant estrogen when used in a conventional manner, the OCP provides supraphysiological levels for 3 weeks and then none for 1 week when the patient may be symptomatic of estrogen deficiency.

$17-\beta$ estradiol is the naturally occurring human estrogen (6), which is variably absorbed and undergoes hepatic transformation to the less active estrone. Ethinyl estradiol is a synthetic analog of 17- $\beta$ estradiol, and the ethinyl substitution at the C-17 site inhibits first-pass metabolism. ethinyl estradiol also binds irreversibly to the estrogen receptor, resulting in a longer action, and accordingly, a much smaller dose of ethinyl estradiol is needed (7). The relative potency of ethinyl estradiol and 17- $\beta$ estradiol varies amongst the different actions of estrogen. No comparative studies have been carried out on these two agents with regards to their effects on secondary sexual characteristics, height velocity and bone maturation. Measurement of a highly estrogen-inducible plasma protein (the pregnancy zone protein/pregnancyassociated alpha 2-globulin (PZP/PA $\alpha 2 \mathrm{G})$ ) in postmenopausal women suggests that ethinyl estradiol has a potency 500 times more than 17- $\beta$ estradiol and 650 times more than estradiol valerate (8). Estimates from the pharmaceutical company (Solvay Healthcare Ltd personal communication), however, suggest that $1 \mu \mathrm{g}$ ethinyl estradiol is equivalent to $100-250 \mu \mathrm{g} 17-\beta$ estradiol. The administration of $2 \mathrm{mg} 17-\beta$ estradiol as opposed to $2 \mu$ g ethinyl estradiol would therefore appear to result in an approximately four to tenfold increase in the intended estrogen dose. As with our girls, this may cause an estrogen-induced uterine bleed with associated anxiety 
for the child and their parents. It could also potentially reduce the patient's final height by accelerating epiphyseal fusion, and it is noteworthy that all children have now stopped growing, and four of five have achieved final heights below $152 \mathrm{~cm}$. Moreover, the two girls who had bone ages performed prior to their estrogen overdose have reductions in their final height compared to prediction of $2.6 \mathrm{~cm}$ (Patient 2) and $6.9 \mathrm{~cm}$ (Patient 4) respectively. It is not standard policy to perform routine bone ages in girls with Turner syndrome, and the third patient with hypopituitarism (Patient 5 ) only had bone ages performed after her estrogen overdose; so, height predictions are not possible to estimate in these three patients. Whilst highdose estrogen has been used in order to reduce final height in tall girls $(9,10)$, short stature may also reflect their underlying disorder rather than any adverse effects of treatment. This is particularly true for the girls with Turner syndrome, as this condition is associated with a reduction of approximately $20 \mathrm{~cm}$ in final height (5). Short stature and pubertal problems are also well-recognised in $\beta$-thalassemia major, the former due to dysfunction within the GH-IGF1 axis and chelation-related bone dysplasia, with hypogonadism usually due to gonadotropin deficiency secondary to iron overload (11). In addition, longterm high-dose estrogen treatment has also now been implicated with sub-fertility (9) as well as malignant and non-malignant tumours in adulthood (10). Although our patients were treated for shorter period of time than these groups, long-term surveillance will be necessary. Apart from patient 4 who is currently transitioning, all of these patients have now been moved to adult care, where ongoing follow-up (including of fertility) will be carried out.

There are few drugs where formulations are available in microgram or milligram doses, leading to the potential for such mistakes being made. An email sent to members of the British Society for Paediatric Endocrinology and Diabetes (BSPED) has revealed a number of additional patients who had similar mistakes (personal communication). As with our patients, this has often arisen for a variety of reasons, including the medication and dose being transcribed incorrectly or simply the wrong dose being given. It is important to be aware of this potential clinical risk when managing such patients. Whilst hospital-only prescribing of ethinyl estradiol, which has been implemented in both ours and other pediatric endocrine units, has reduced the frequency of misprescribing, it has not been able to abolish dispensing errors such as occurred in the fourth patient.
In conclusion, whilst ethinyl estradiol provides a readily available and convenient mode of pubertal induction and HRT in hypogonadal girls, clinicians need to be aware of the potential for patients to receive inappropriate doses of natural estrogens in error.

\section{Declaration of interest}

The authors declare that there is no conflict of interest that could be perceived as prejudicing the impartiality of the research reported.

\section{Funding}

This research did not receive any specific grant from any funding agency in the public, commercial or not-for-profit sector.

\section{Author contribution statement}

Author contributions and $\mathrm{N}$ Wickramasuriya wrote the initial report. N J Shaw and J M W Kirk submitted cases and also rewrote the paper for publication. N Wickramasuriya was the registrar who collated the cases and wrote the initial draft.

\section{Patient consent}

Written informed consent was obtained from the patients for publication of the submitted article.

\section{References}

1 Spiliotis BE 2006 Growth and long-term hormonal therapy. Pediatric Endocrinology Reviews 3 (Suppl 1) 192-194.

2 Bath L, Critchley H, Kelnar C \& Wallace H 2001 Choice of hormone replacement therapy in young women with ovarian failure. Clinical Endocrinology 55 697-698. (doi:10.1046/j.1365-2265. 2001.01370 3.x)

3 Gault E \& Donaldson M 2009 Oestrogen replacement in Turner's syndrome: current prescribing practice in the UK. Clinical Endocrinology 71 753-755. (doi:10.1111/j.1365-2265.2009.03579.x)

4 Rosenfeld RL, Devine N, Julius K, Mauras N, Moshang T \& Root A 2005 Salutary effects of combining early very low dose systemic estradiol with growth hormone therapy in girls with Turner Syndrome. Journal of Clinical Endocrinology and Metabolism 90 6424-6430. (doi:10.1210/jc. 2005-1081)

5 Royal College of Obstetrics and Gynaecology (RCOG) 2013 Sex Steroid Treatment for Pubertal Induction and Replacement in the Adolescent Girl. Scientific Impact Paper No. 40 https://www.rcog. org.uk/globalassets/documents/guidelines/scientific-impact-papers/ sip_40.pdf.

6 Lieberman S 1996 Are the differences between estradiol and other estrogens, naturally occurring or synthetic, merely semantical? Journal of Clinical Endocrinology and Metabolism 81 850-853. (doi:10.1210/jcem.81.2.8636315)

7 Jensen EV, Jacobson HI, Flesher JW, Saha NN, Gupta GN, Smith S, Colucci V, Shiplacoff D, Neumann HG, Desombre ER, Jungblut PW 1966 Estrogen receptors in target tissues. In T Nakao, G Pincus, J Tait, Eds. Steroid Dynamics. New York, NY: Academic Press pp 133-157. 
Endocrinology

Diabetes \& Metabolism

CASE REPORT
J M W Kirk and others

Micrograms or milligrams

formulations
8 Helgason S, Damber MG, von Schoultz B \& Stigbrand T 1982 Estrogenic potency of oral replacement therapy estimated by the induction of pregnancy zone protein. Acta Obstetrica Gynecologica Scandinavica 61 75-79. (doi:10.3109/00016348209156956)

9 Hendriks AE, Laven JS, Valkenburg O, Fong SL \& Fauser BC 2011 Fertility and ovarian function in high-dose estrogen treated tall women. Journal of Clinical Endocrinology and Metabolism 96 1098-1105. (doi:10.1210/jc.2010-2244)
10 Benyi E, Kieler H, Linder M, Ritzén M, Carlstedt-Duke J, Tuverno T, Westphal O \& Savendahl L 2014 Risks of malignant and non-malignant tumours in tall women treated with high-dose oestrogen during adolescence. Hormone Research in P?diatrics 82 89-96. (doi:10.1159/ 000360137)

11 Raiola G, Galati MC, De Sanctis V, Caruso Nicoletti M \& Pintor C 2003 Growth and puberty in thalassemia major. Journal of Pediatric Endocrinology and Metabolism 16 (Suppl 2) 259-266.

Received in final form 20 December 2015

Accepted 6 January 2016 